\title{
Cerebral Venous Thrombosis in an Adolescent with Celiac Disease
}

Sara Sabiry", Salma Louzi, Zainab Abdulhakeem, Hicham EL Otmani, Mohamed Abdoh Rafai, Bouchra EL Moutawakil

Hassan II University of Casablanca, Department of neurology and Clinical neurophysiology, IBN ROCHD University Hospital of Casablanca, Morocco

DOI: $10.36347 /$ sjmcr.2020.v08i04.024

| Received: 15.04.2020 | Accepted: 22.04.2020 | Published: 30.04.2020

*Corresponding author: Sara Sabiry, MD

Abstract

Celiac disease (CD) is a gluten-induced or gluten-sensitive enteropathy. It is considered as a chronic autoimmune disease affecting the gastrointestinal tract leading to malabsorption. CD may also affect other systems and it has been described as a disease associated with both arterial and venous thrombotic events. In this presentation, we report a case of a 16-year-old girl who had CD and cerebral venous thrombosis (CVT). We emphasized that CD can be investigated in patients with CVT and it is essential to search for risk factors.

Keywords: Celiac disease, cerebral venous thrombosis, deep venous thrombosis.

Copyright @ 2020: This is an open-access article distributed under the terms of the Creative Commons Attribution license which permits unrestricted use, distribution, and reproduction in any medium for non-commercial use (NonCommercial, or CC-BY-NC) provided the original author and source are credited.

\section{INTRODUCTION}

Celiac disease (CD) is a gluten-induced or gluten-sensitive enteropathy. It is considered as a chronic autoimmune disease affecting the gastrointestinal tract, mainly small intestines, of genetically susceptible individuals, causing malabsorption.

CD may also affect other systems leading to extra intestinal manifestations. Thus; neurological, psychiatric, cutaneous, endocrine, hepatic, skeletal and dental, hematological, oncological, infertility as well as gynecological disorders are continually reported $[1,2]$.

The incidence of CD-related neurological manifestations has been estimated at 6-10\% [1]. Including epilepsy, cerebellar ataxia, central nervous system degenerative disorders and dementia. As for peripheral neuropathy, myopathy, and stroke, they have been rarely reported.

CD has been described as a disease associated with both arterial and venous thrombotic events. Portal vein or Budd-Chiari syndrome caused by abdominal venous thrombosis is the frequently observed condition. CD-related cerebral venous thrombosis (CVT) has been scarcely reported in the literature, especially in adolescents [3, 4]. Pathogenesis is multifactorial and not well known. We report a case of a 16-year-old girl who had CD and CVT.

\section{Case Report}

A 16-year-old girl, with a history of recurrent untreated diarrhea since the age of 6 , was admitted to our department with a two-week' history of an acute headache, visual blurring, photophobia without vomiting, associated with confirmed deep venous thrombosis of the left common iliac vein.

The patient reported that, five months earlier, her gastrointestinal symptoms exacerbated leading to dehydration and secondary amenorrhea.

Physical examination revealed normal vital signs, conjunctival and skin pallor with a severely low body mass index at 13,6. Ophthalmic examination noted a stage 1 papilledema and normal visual acuity. Both the neurological and somatic examination was unremarkable.

Brain MRI showed left transverse sinus thrombosis (Figure 1). Lumbar puncture revealed elevated CSF pressure (28 cm H2O) with normal CSF analysis.

Blood testing found a malabsorption syndrome with iron deficiency (microcytic hypochromic anemia at $10.8 \mathrm{~g} / \mathrm{dl}$ ), normal vitamin B12 and homocysteine levels, hypocalcemia at $77 \mathrm{mg} / \mathrm{L}$ (normal: 90-105 $\mathrm{mg} / \mathrm{L}$ ), hypoalbuminemia at 18,1 g/L (normal: $39-49 \mathrm{~g} / \mathrm{L}$ ) and hypoprothrombinemia (58\%). Serum glucose, liver and renal function tests, cholesterol and triglyceride levels, erythrocyte sedimentation rate and thyroid hormone 
values were within normal range. C-reactive protein was negative. Feces analysis and abdominal ultrasound were normal.

Checking for a factor V Leiden, MTHFR and prothrombin 20210 gene mutations, lupus anticoagulant, anticardiolipin, antinuclear and antiDNA antibodies were negative. But low levels of antithrombin III, protein $\mathrm{C}$ and $\mathrm{S}$ were noted. Anti- tissue transglutaminase and anti-endomysium antibodies were positive. Gastroesophageal endoscopy and duodenal biopsy revealed villous atrophy. The diagnosis of $\mathrm{CD}$ was confirmed, and gluten free diet was started. The patient received adequate anticoagulant therapy (heparin then lifelong vitamin $\mathrm{K}$ antagonists (VKA) and symptomatic treatments. A favorable long-term outcome was noted. The patient gained weight and remained symptom free.

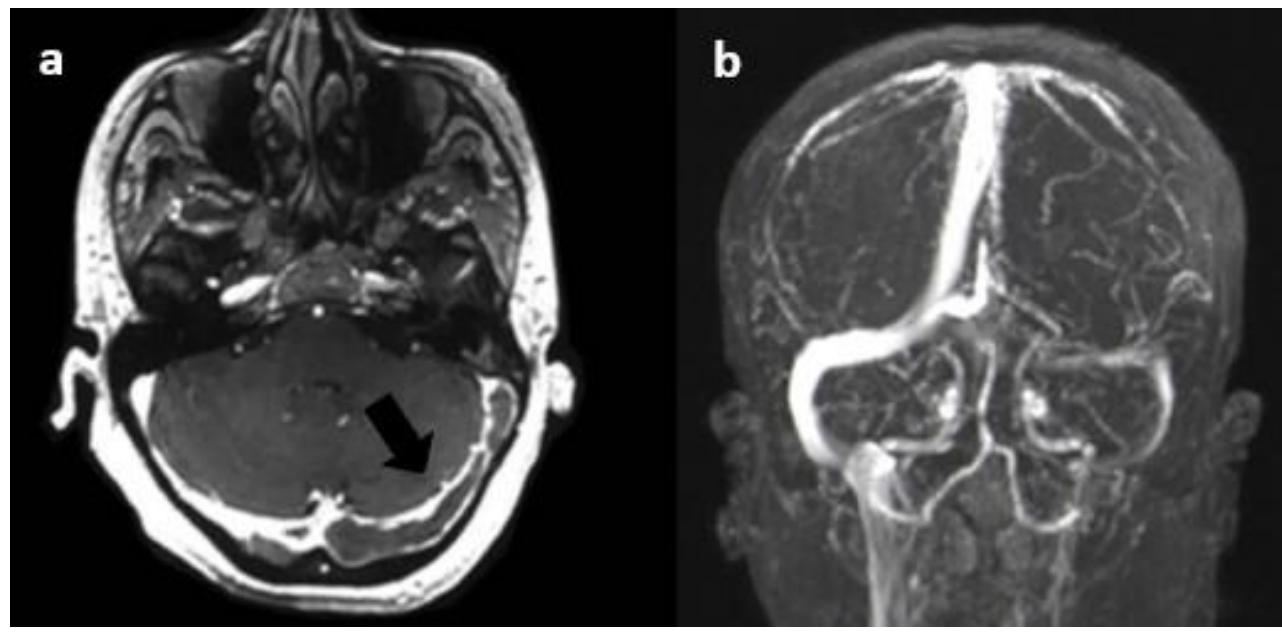

Fig-1: Brain MRI: a) Axial T1-weighted MRI with contrast and b) MR angiography; showed CVT of the left transverse sinus

\section{DISCUSSION}

$\mathrm{CD}$ is no longer considered a childhood malabsorption syndrome, this autoimmune disease can affect individuals at any time across their lifespan. The disorder is frequently unrecognized by physicians, in part because of its variable clinical presentations and symptoms. CD is easily diagnosed in children with symptomatic malabsorption syndrome but most of them lack this symptom and the clinical picture varies widely at presentation. Genetic, immunological and environmental factors are necessary for the expression of the disease [5].

Classical forms revealed by the triad malabsorption, diarrhea and abdominal pain represent only $10-20 \%$ of cases and clinical presentation is often polymorphic [6]. Neurological presentations are rare in children. Whereas, as many as $36 \%$ of adult patients present with neurological changes [7].

The occurrence of thrombosis in cerebral veins during CD remains poorly described. Ungprasert et al, concluded to a significant increase in the risk of encountering thromboembolic events in patients with CD [8]. The pathogenesis of this association is not well defined. It seems, however, that it is related to a hypercoagulability state. Multiple pathogenic pathways [3] and various hypothesis have been proposed: hyperhomocysteinemia secondary to folic acid deficiency due to the malabsorption syndrome was the primary risk factor for venous thromboembolism, protein $\mathrm{C}$ and $\mathrm{S}$ deficiency secondary to vitamin $\mathrm{K}$ malabsorption and thrombocytosis leading to blood's hyperviscosity [9].

Further on, several autoimmune disorders are associated with thromboembolic phenomenon during $\mathrm{CD}$ but the antiphospholipid syndrome (APS) is the most known one. In fact, autoimmune disorders (lupus erythematosus and APS) associated with CD, increase the hypercoagulability state as a result of high levels of circulating antibodies $[10,2]$.

Other mechanisms are still debated, and controversial. Another widely incriminated factor is autoimmune central nervous system vasculitis, in which tissue transglutaminase, the main auto-antigen contributing to maintaining the integrity of endothelium tissue, plays a major role [11].

The initially reported risk factors for stoke and CVT in the pediatric population are: Dehydration, local head and neck or systemic infections, congenital heart disease, and anemia. Whereas, genetic and acquired prothrombotic disorders have, later, been highlighted $[12,13]$.

Etiologic investigation, in our case, revealed double protein $\mathrm{C}$ and $\mathrm{S}$ deficit. This latter could be explained by vitamin $\mathrm{K}$ deficiency secondary to malabsorption, leading to a thrombophilic status [14]. Other prothrombotic risk factors and predisposing conditions are high level factor VIII, low factor XII, factor V Leiden, prothrombin 20210 and homozygote 
MTHFR mutations, as well as high levels anticardiolipin $\operatorname{IgG}$ antibodies.

The majority of reported cases, in the literature, were treated with anticoagulation and all with Gluten free diet (GFD) including our patient, but no guidelines exist concerning the VKA's duration to be considered in these cases. In some patients with recurrent thrombosis, lifelong anticoagulation was decided. Lee et al, showed that the intestinal mucosa does not recover completely and inflammation does not quiet resolve despite strict GFD up to 2 years following diagnosis [9]. Thus, we decided to maintain a lifelong VKA in our patient.

\section{CONCLUSION}

In the light of this knowledge, it is established that there is a tendency toward thromboembolic events in patients with $\mathrm{CD}$, especially during acute exacerbation periods. Further studies should focus on the overall relative risk of thromboembolic episodes in patients with celiac disease and identify those patients who need thrombo-prophylaxis.

\section{REFERENCES}

1. Bushara KO. Neurologic presentation of celiac disease. Gastroenterology. 2005; 128 (Suppl.1) : S92-7.

2. Lerner A, Blank M. Hypercoagulability in celiac disease-An update. Autoimmun Rev. 2014, http://dx.doi.org/10.1016/ j.autrev.2014.07.004

3. Beyrouti R. Recurrent cerebral venous thrombosis revealing celiac disease: an exceptional case report. Acta Neurologica Belgica. 2017. 117(1): p. 341-343.

4. Bahloul M, Chaari A, Khlaf-Bouaziz N, Kallel H, Chaari L, Hamida CB, Chelly H, Rekik N, Bouaziz M. Maladie cœliaque, thrombose veineuse cérébrale et déficit en protéine $S$, Une association fortuite?. Journal des maladies vasculaires. 2005 Sep 1;30(4):228-30.

5. M. Luisa Mearin. Celiac Disease Among Children and Adolescents. Curr Probl Pediatr Adolesc Health Care. 2007;37:86-105
6. Jomni T, Bellakhal S, Abouda M, Abdelaali I, Douggui $H$. Une présentation atypique de la maladie coliaque: l'occlusion de la veine centrale de la rétine. Pan African Medical Journal. 2015;22(1).

7. Chaudhry V, Ravich WJ. Neurology and General Medicine. 3th ed. New York, NY: Churchill Livingstone; 2001. Other neurological disorders associated with gastrointestinal, liver, or pancreatic diseases; 2001: 283-4

8. Ungprasert P, Wijarnpreecha K, Tanratana P. Risk of venous thromboembolism in patients with celiac disease: A systematic review and meta- analysis. Journal of gastroenterology and hepatology. 2016 Jul;31(7):1240-5

9. Dumic, S. Martin, N. Salfiti. Thrombose veineuse profonde et embolie pulmonaire bilatérale révélant la maladie coeliaque silencieuse: rapport de cas et revue de la littérature. Case Reports in Gastrointestinal Medicine Volume. 2017, 8.

10. Laine $\mathrm{O}$, Pitkänen $\mathrm{K}$, Lindfors $\mathrm{K}$, Huhtala $\mathrm{H}$, Niemelä O, Collin P, Kurppa K, Kaukinen K. Elevated serum antiphospholipid antibodies in adults with celiac disease. Digestive and Liver Disease. 2018 May 1;50(5):457-61.

11. El BM, Chourkani N, Sibai M, Moutaouakil F, Rafai M, Bourezgui M, Slassi I. Celiac disease and ischemic stroke. Revue neurologique. 2009 Nov;165(11):962-6.

12. Doğan M, Peker E, Akbayram S, Bektas MS, Basaranoglu M, Cesur Y, Caksen H. Cerebral venous sinus thrombosis in 2 children with celiac disease. Clinical and Applied Thrombosis/Hemostasis. 2011 Oct;17(5):466-9.

13. Sébire G, Tabarki B, Saunders DE, Leroy I, Liesner R, Saint-Martin C, Husson B, Williams AN, Wade A, Kirkham FJ. Cerebral venous sinus thrombosis in children: risk factors, presentation, diagnosis and outcome. Brain. 2005 Mar $1 ; 128(3): 477-89$.

14. Boucelma M, Saadi M, Boukrara H, Bensalah D, Hakem D, Berrah A. Association of celiac disease and cerebral venous thrombosis: report of two cases. Journal des maladies vasculaires. 2013 Feb;38(1):47-51. 